\title{
Diagnosing the Intercept Parameters of the Exponential Drop Size Distributions in a Single-Moment Microphysics Scheme and Impact on Supercell Storm Simulations
}

Charlotte E. Wainwright ${ }^{1,2}$, Ming Xue ${ }^{1,2}$, Guifu Zhang ${ }^{1}$ and Daniel T. Dawson, II $^{3}$

${ }^{1}$ School of Meteorology and ${ }^{2}$ Center for Analysis and Prediction of Storms

${ }^{3}$ NOAA/National Severe Storms Laboratory, National Weather Center 120 David L. Boren Blvd.

Norman, OK 73072

December 2011

Submitted to Journal of Applied Meteorology and Climatology
Revised July 2012

Corresponding author address:

Ming Xue

Center for Analysis and Prediction of Storms

University of Oklahoma

120 David L. Boren Blvd, Suite 2500

Norman, OK 73072, USA

E-mail:mxue@ou.edu 
In this study, power-law relations are developed between the intercept parameter of the

41 exponential particle size distribution and the water content for the rain, hail, graupel and snow

42 hydrometeor categories. The derived relations are implemented within the Milbrandt and Yau 43 microphysics scheme. Simulations of the 3 May 1999 Oklahoma tornadic supercell are

44 performed using the diagnostic relations for rain only, and alternately for all four precipitating 45 species, and results are compared with those from the original single- and double-moment 46 versions of the microphysics schemes. Diagnosing the intercept parameter for rain is found to 47 improve the results of the simulation in terms of reproducing the key features of the double48 moment simulation while still retaining the computational efficiency of a single-moment scheme.

49 Improvements were seen in general storm structure, cold pool structure and intensity, and the 50 number concentration fields. Diagnosing the intercept parameters for all four species, including 51 those for the ice species, within the single-moment scheme yields even closer alignment with the 52 double-moment simulation results. The decreased cold pool intensity is very similar to that 53 produced by the double-moment simulation, and the areal extent of the storm is more accurately 54 reproduced. This study suggests that significant improvements over traditional fixed-intercept 55 parameters in typical single-moment microphysics schemes can be achieved through the use of 56 diagnostic relations for the parameters of the particle size distribution, without a significant 57 increase in computational cost. 


\section{Introduction}

As numerical weather prediction (NWP) models gain convection-resolving resolutions of

$601 \mathrm{~km}$ and higher, the parameterization of microphysical processes becomes critical, especially for

61 precipitation forecasts. Generally, bulk microphysics parameterizations, which specify a

62 particular size distribution for each hydrometeor species and predict certain moments of the size

63 distribution (e.g., the water mass proportional to the third moment of the size distribution), are

64 used due to the comparatively high cost of non-bulk spectral or bin models for simulations of

65 three-dimensional moist convection.

66 The most commonly used particle size distribution (hereafter PSD) for precipitating

67 hydrometeors is the inverse exponential distribution, which can be written as

$$
N(D)=N_{0} \exp (-\Lambda D)
$$

69 where $N_{0}$ is the intercept parameter and $\Lambda$ is the slope parameter of the PSD. Usually the 70 intercept parameter is assigned a fixed value in single-moment microphysics schemes. The most 71 well-known of these exponential distributions is the Marshall-Palmer (Marshall and Palmer

72 1948) distribution, which specifies $N_{0}$ to be $8 \times 10^{6}$ drops $\mathrm{m}^{-4}$ for rain. However, using this fixed

73 value for the rain intercept parameter has been shown to be restrictive, as the intercept parameter

74 can vary significantly within single precipitation events both spatially and temporally (Tokay and

75 Short 1996; Zhang et al. 2008). Snook and Xue (2008) investigated the effect of varying $N_{0}$ for

76 the rain and hail particle size distributions (PSDs) on storm evolution within high-resolution

77 supercell simulations, focusing on the effect upon tornadogenesis. It was found that in

78 simulations where $N_{0}$ was lowered such that the PSD favored large drops, the resulting cold

79 pools were weaker and the simulations tended to develop into single or multiple supercells, while

80 when $N_{0}$ was raised, the storms transformed to a linear mode during the simulations. Tornado- 
81 like low-level vortices formed in the low- $N_{0}$ simulations but not in others. Cohen and McCaul

82 (2006) performed simulations using an increased median volume diameter for hail and graupel,

83 equivalent to decreasing the slope parameter for those species, which resulted in reduced low-

84 level cooling due to decreased melting. Earlier studies of van den Heever and Cotton (2004) and

85 Gilmore et al. (2004) also found significant sensitivity of simulated supercell storms to PSD

86 parameters. More recently, Van Weverberg et al. (2010; 2011a) also investigated the impact of

87 PSDs in single-moment microphysics scheme on precipitation and storm dynamics, and the

88 sensitivity of simulated precipitation systems to microphysics complexity (Van Weverberg et al.

89 2011b).

90 The distribution represented by (1) is a subset of the gamma distribution (Ulbrich 1983),

91 which has the form

$$
N(D)=N_{0} D^{\alpha} \exp (-\Lambda D)
$$

93 where $\alpha$ is the shape parameter, a dimensionless measure of the spectral width of the distribution.

94 If $\alpha$ is set to 0 , the distribution is reduced to the inverse exponential form. The addition of the

95 shape parameter allows the gamma distribution to depict a far greater range of PSDs than the

96 inverse exponential distribution. Mallet and Barthes (2009) applied a maximum likelihood

97 technique to categorize rain drop size distributions (DSDs) from optical disdrometer data, and

98 found that $91 \%$ of the measured DSDs were of the gamma type.

99 Each of the parameters of the gamma distribution varies widely in value in nature, thus

100 parameterizing any of them as constant will introduce a source of error into the microphysics.

101 Ulbrich (1983) calculated a typical range of values for $\alpha$ and $N_{0}$ of the rain DSD, encompassing

102 relations derived from $Z-R$ (reflectivity-rain rate) relationships presented in a number of other

103 studies. Calculated values for $\alpha$ varied from -3.42 to 5.04 (the range was far narrower for studies 
104 based on convective rain, with $\alpha$ ranging from 0.40 to 1.63 ) and values for $N_{0}$ ranged from $1.29 \times$

$10510^{3} \mathrm{~m}^{-4}$ to $9.20 \times 10^{12} \mathrm{~m}^{-4}\left(7.05 \times 10^{6} \mathrm{~m}^{-4}\right.$ to $2.46 \times 10^{8} \mathrm{~m}^{-4}$ for convective rain $)$. Although some

106 of the variations in parameter values are due to errors in measurements, modeling, and fitting

107 procedures (Cao and Zhang 2009), variation due to physical causes appears to dominate (Zhang

108 et al. 2003 and Milbrandt and Yau 2005a,b).

109 The role of the shape parameter $\alpha$ was investigated in detail by Milbrandt and Yau

110 (2005a), who showed that the rate of gravitational particle size sorting was dependent on $\alpha$, with

111 the size sorting rate decreasing as $\alpha$ increases and approaching 1 as $\alpha$ becomes large. Size sorting

112 is an intrinsic process within supercell evolution, as witnessed by the occurrence of the

113 differential reflectivity $\left(Z_{\mathrm{DR}}\right)$ arc within supercells. Kumjian and Ryzhkov $(2008,2009)$ found

114 that the $Z_{\mathrm{DR}}$ arc is associated with large, oblate raindrops and relatively few small drops,

115 suggesting that size-sorting is responsible for the modification of the DSD. Hence it is important

116 to parameterize the PSD in a realistic manner, allowing all parameters to vary as appropriate.

117 A way to improve a microphysics scheme is to increase the number of predicted moments

118 of the PSD (Straka and Mansell 2005; Milbrandt and Yau 2005a). How the moments of the PSD

119 are calculated depends on the way the PSD is parameterized. For the gamma distribution the $n^{\text {th }}$

120 moment is calculated as

$$
M_{\mathrm{n}}=N_{0} \Lambda^{-(\alpha+\mathrm{n}+1)} \Gamma(\alpha+\mathrm{n}+1)
$$

122 Most bulk microphysics schemes, especially those used in operational NWP models, only

123 predict one moment of the distribution, typically the third moment $M_{3}$, which is proportional to

124 the hydrometeor mixing ratio, $q_{x}$ (here $x$ denotes one of the species). In this case, it is usually the

125 slope parameter $\Lambda$ that is effectively prognostic while $N_{0}$ and $\alpha$ are held constant (with $\alpha$ fixed at

1260 for the inverse exponential distribution), although in a Thompson et al. (2004) simulation the 
127 intercept parameter for snow is diagnosed based on temperature. More recently, microphysical

128 schemes that predict two or more moments have become increasingly popular, particularly for 129 convective scale modeling. Most of the double-moment schemes available predict both the 130 mixing ratio and number concentration, leaving $\alpha$ held constant while $N_{0}$ and $\Lambda$ are directly 131 linked to the predicted variables (e.g., Milbrandt and Yau 2005a; Morrison et al. 2005). Aside from moving to multi-moment schemes, which are computationally expensive, 133 other methods of extending low-moment schemes beyond the fixed single-parameter approach 134 have been attempted. The most common method relates a free parameter in the PSD to another 135 independently predicted PSD parameter. Zhang et al. (2001) investigated relations between the 136 PSD parameters using video disdrometer data collected in Florida and derived a relation between 137 the shape and slope parameters. The $\alpha-\Lambda$ relation was subsequently updated using disdrometer 138 measurements for rain DSDs observed in Oklahoma (Cao et al. 2008).

139 Zhang et al. (2008) used the same disdrometer data as Cao et al. (2008), gathered in 140 central Oklahoma during the summers of 2005 through 2007, to derive a relationship between 141 the intercept parameter of the inverse exponential PSD and the rain water content (which is 142 proportional to the third moment of the distribution). The diagnostic relation was formed using 143 the method of moment relations, outlined in detail in their paper. Their derived relation for rain 144 was $N_{0}\left(M_{2}, M_{4}\right)=7106 W^{0.648}$, where $N_{0}$ is measured in $\# \mathrm{~m}^{-3} \mathrm{~mm}^{-1}$ and $W$ is in $\mathrm{g} \mathrm{m}^{-3}$. Here $N_{0}$ is 145 given as a function of $M_{2}$ and $M_{4}$ because its relation is derived from these two moments.

146 In the single-moment version of the Milbrandt and Yau microphysics scheme (Milbrandt 147 and Yau 2005b, hereafter MY), described in more detail in section 3, the PSD of each 148 precipitating hydrometeor category is modeled by a gamma distribution with a fixed value of $\alpha$. 
149 In this paper, we assume $\alpha$ to be zero, leading to the exponential distribution commonly used in 150 single moment schemes.

151 Given the moment relation in (3) and setting $\alpha$ to zero, we see that the exponential PSD

152 parameters, $N_{0}$ and $\Lambda$, can be determined using any two moments of the distribution. Given any

153 two moments, $M_{\mathrm{j}}$ and $M_{\mathrm{k}}$, the PSD parameters can be calculated as

$$
N_{0}=\frac{M_{j} \Lambda^{j+1}}{\Gamma(j+1)},
$$

$$
\Lambda=\left[\frac{M_{j} \Gamma(k+1)}{M_{K} \Gamma(j+1)}\right]^{\frac{1}{k-j}} .
$$

The moment estimates from disdrometer measurements contain errors (Zhang et al. 157 2008), causing errors in the DSD parameters determined from them. The middle (second and 158 fourth) moments were used in their study as they contain the least error (Cao and Zhang 2009).

159 The main issue with these observation-based studies is that the diagnostic relations are derived 160 using disdrometer data collected at the surface, primarily for rain. Diagnostic relations derived 161 from three-dimensional data sets for individual species are needed for use within microphysics 162 parameterization schemes.

163 The goal of this study is to formulate and test diagnostic relationships between the

164 intercept parameter and water/ice content for each precipitating hydrometeor species, and 165 implement this within the single-moment MY microphysics scheme (Milbrandt and Yau 2005b) 166 available within the ARPS nonhydrostatic model (Xue et al. 2000; Xue et al. 2001). It is 167 hypothesized that this should allow a more realistic PSD model than the use of a fixed value of $168 N_{0}$ for each precipitating hydrometeor species, and will enable a more accurate representation of 169 the PSDs. To this end, the overall aim of the study is to improve the results of the single-moment 
170 microphysics scheme for them to be closer to the results of the corresponding double-moment

171 microphysics scheme. For the derivation of the PSD parameter relationships in this study, the

172 zeroth and third moments of the inverse exponential PSD are used since these are independently

173 predicted within the double-moment MY microphysics scheme. As the first proof-of-concept

174 attempt and because of the general lack of DSD observations for multiple species in 3D volumes,

175 we use the output of the Milbrandt and Yau double-moment simulations to derive the relations.

176 We use a realistic simulation of a real tornadic supercell storm for the test. The case is described

177 next.

178 The remainder of the paper is organized as follows: the case being simulated is described

179 in section 2. The formulation of the diagnostic intercept parameter relationships is covered in

180 section 3. The setup used for the numerical experiments is described in section 4 . Section 5

181 includes results of the experiments and discussion. Section 6 summarizes the results and

182 discusses future work.

183

184 2. The May $3^{\text {rd }} 1999$ Oklahoma tornadic supercell case

185 On May $3^{\text {rd }} 1999$, one of the most significant tornado outbreaks ever to occur in the U.S. 186 caused extensive damage across Oklahoma and Kansas, including the metropolitan areas of 187 Oklahoma City and Wichita. Fifty eight tornadoes struck within the county warning area of the 188 Norman, Oklahoma National Weather Service Forecasting Office over a period of eight hours 189 (Speheger et al. 2002). Sixteen of these tornadoes were rated F2 or greater on the Fujita (1971) 190 scale, including two F4 and one F5 tornadoes.. The F5 tornado tracked through the small 191 community of Bridge Creek, parts of Moore, southern Oklahoma City, Del City and Midwest 192 City, causing 36 direct fatalities (Brooks and Doswell 2002) and injuring 583 people. The storm 193 that produced the F5 tornado is the focus of this study. 
195 pools associated with the supercell which produced the F5 tornado were mainly small and

196 relatively weak. The synoptic setup for the event has been discussed in detail in Thompson and

197 Edwards (2000) and Roebber et al. (2002).

Given the inherent instability present, a gap in the cirrus cloud cover allowed a cumulus

199 tower to develop close to Lawton in Southwestern Oklahoma, around 2030-2045 UTC. This

200 evolved into the first supercell and after an initial split, rapidly developed into a right-moving 201 supercell - storm A (Thompson and Edwards 2000). Storm A became tornadic and produced at 202 least fourteen distinct documented tornadoes between 2151 UTC on May 3 and 0125 UTC on 203 May 4 (Speheger et al. 2002). The most intense of the tornadoes produced by storm A was A9, 204 the F5 tornado that left a 37-mile trail of destruction through the communities of Bridge Creek, 205 Moore and Oklahoma City. Dawson et al. (2010) simulated a supercell storm within an 206 environment believed to be representative of the environment that storm A developed, and the 207 study found significant sensitivity of the simulated supercell storm to the number of moments 208 predicted with versions of the MY scheme. The predicted cold pool was generally too strong 209 with the single moment scheme while the simulation of the three-moment scheme was found to 210 be the best.

\section{Diagnostic relations for intercept parameters}

213 The ARPS implementation of the double-moment MY microphysics scheme has two 214 options, schemes 2 and 2a (hereafter referred to as MY2 and MY2a). Scheme 2 fixes the shape 215 parameter of the gamma distribution, $\alpha$, to a constant value; when $\alpha$ is set to zero this reduces to 216 the inverse exponential distribution. Scheme 2 a diagnoses $\alpha$ for each sedimenting hydrometeor 217 species based upon the mean mass diameter $D_{m x}$, in the form $\alpha_{x}=c_{1 x} \tanh \left[c_{2 x}\left(D_{m x}-c_{3 x}\right)\right]+c_{4 x}$, 
218 where $D_{m x}$ is in units of $\mathrm{mm}$ and $\mathrm{c}_{1 x}$ through $\mathrm{c}_{4 x}$ are empirically determined coefficients, detailed

219 in their Table 1 (Milbrandt and Yau 2005a), allowing variability in the PSD shape.

220 As pointed out earlier, DSD observations for multiple species in 3D volumes are

221 generally unavailable, making it difficult to obtain diagnostic relations for several species that

222 are applicable to the entire storm. As the first proof-of-concept attempt, we use the output of a

223 double-moment simulation for the May 3, 1999 case to derive diagnostic relations for use in a

224 single-moment scheme. This allows us to see how close the results of single-moment scheme

225 with diagnostic relations can be to those of double-moment scheme.

226 Using a single sounding to define the storm environment, Dawson et al. (2010) have

227 shown for the May 3, 1999 case, the simulated supercell is rather sensitive to the use of single,

228 double and triple moment options of the Milbrandt and Yau scheme. A similar sensitivity to the

229 moment of the MY scheme used was shown for another supercell simulation in Milbrandt and

230 Yau (2006). Dawson (2009) further performed more realistic simulations of this case using 3D

231 inhomogeneous initial conditions that included the assimilation of radar data. The simulation

232 used three levels of nested grids, at $3 \mathrm{~km}, 1 \mathrm{~km}$ and $250 \mathrm{~m}$ horizontal grid spacings, respectively.

233 The North America Regional Reanalysis (NARR) provided the initial analysis background and

234 the boundary conditions for the outermost $3 \mathrm{~km}$ grid. The assimilation of Oklahoma City WSR-

235 88D (KTLX) radar data was performed on the $1 \mathrm{~km}$ grid, using ARPS Data Analysis System

236 (ADAS) (Brewster 1996) that includes a complex cloud analysis component. The cloud analysis

237 makes use of satellite and radar observations to define cloud and hydrometeor fields and adjust

238 in-cloud temperature and moisture fields (Hu et al. 2006). Conventional observations were

239 analyzed using a successive correction scheme that converges to an optimal interpolation

240 solution (Brewster 1996; Lazarus et al. 2002). These simulations were performed using a full set 
241 of physics in the ARPS (Xue et al. 2001). Details of these simulations can be found in Dawson 242 (2009).

243 In this study, the output of the $250 \mathrm{~m}$ simulation using the MY2 scheme with $\alpha$ set to 244 zero from that study is used as a "synthetic dataset" to derive the diagnostic relations for the 245 intercept parameters. This simulation will hereafter be referred to as the "reference" simulation.

246 The simulation using MY2 instead of MY2a is chosen as the reference to avoid the complication

247 of non-zero $\alpha$ that changes the physical interpretation or even the unit of the intercept parameter.

248 The derived diagnostic relations are then implemented in the single-moment option of the MY 249 scheme for the various experiments in this study.

250 Model output was taken every 300 seconds throughout the second hour of the reference 251 simulation and collated. For each of the thirteen times, a file containing the zeroth and third 252 moment was produced for each precipitating hydrometeor category, which in the Milbrandt and 253 Yau suite of microphysics schemes includes rain, snow, graupel and hail. Data at grid points in 254 the full domain were included in the file, although since vertical grid stretching was employed, 255 the low levels are more heavily sampled than the upper levels. Points were included provided 256 that a minimum threshold of hydrometeor mixing ratio was met. This threshold was purposely 257 kept low at $1 \times 10^{-5} \mathrm{~kg} \mathrm{~kg}^{-1}$ for rain and $5 \times 10^{-5} \mathrm{~kg} \mathrm{~kg}^{-1}$ for snow, graupel and hail, in order to 258 accurately represent the full range of mixing ratios produced by the simulation. For each point, 259 the parameters of the inverse exponential distribution were calculated and the mass content $W$ 260 was derived using

$$
W_{\mathrm{x}}=1000 \rho_{\mathrm{a}} q_{\mathrm{x}}
$$

262 where $W_{x}$ is in $\mathrm{g} \mathrm{m}^{-3}$, air density $\rho_{\mathrm{a}}$ is in $\mathrm{kg} \mathrm{m}^{-3}$ and mixing ratio $q_{x}$ is in $\mathrm{kg} \mathrm{kg}^{-1}$. As in Zhang et 263 al. (2008), we wish to form a power-law relation between the water content and the intercept 
264 parameter of the exponential distribution for each species. In our case, these relations are

265 calculated by performing a least squares minimization on both variables to give an effective

266 linear relation between the logarithms of the variable pair. Transforming the variables back from

267 logarithmic into linear space provides a power law for $N_{0 x}$ in terms of $W_{x}$. The coefficient and

268 power of the derived $N_{0 x}-W_{x}$ relationships were averaged across the model output times

269 examined in order to give a more general relation for each precipitating hydrometeor category.

270 The plot showing an example of the dependence of $N_{0 r}$ on $W_{r}$ from a single model time exhibits a

271 high degree of scatter (Fig. 1.) However, the powers and coefficients of the derived relationship

272 did not vary significantly across the range of times examined (not shown), which suggests

273 confidence in the robustness of the derived relation.

274 The Milbrandt and Yau suite of microphysics schemes contains four frozen hydrometeor 275 categories - ice, snow, graupel and hail - and each of these is handled separately within the ice 276 phase processes. The ice total number concentration, $N_{t i}$, is already diagnosed based upon 277 temperature in the single-moment option, through Cooper's equation (Cooper, 1986),

$$
N_{t i}=5 \exp (0.304(273.15-\max (233, T))),
$$

279 where $T$ is the temperature in Kelvin. For rain and the other three frozen categories, the number 280 concentration is calculated as the zeroth moment of the distribution using the intercept parameter 281 of the PSD of that species, which is set to a constant value for each species in the original single282 moment microphysics scheme (see Table 1). The scatter plots showing the dependence of $N_{0 x}$ on $283 W_{x}$ for snow, graupel and hail are shown in Figs. 2 through 4. The frozen hydrometeor 284 concentrations are diagnosed based upon the water content within that hydrometeor category. 285 The fixed $N_{0}$ values used in the original Milbrandt and Yau scheme and the fitted relation are 286 also shown in the figures. Examining Figs. 1-4 and Table 1, it is clear that for each of the 
287 hydrometeor species the coefficient differs significantly from the fixed value of $N_{0 x}$, by up to 288 three orders of magnitude in the case of graupel.

\section{Numerical experiments}

291 In order to test the diagnostic $N_{0}$ relations, several simulations of the May $3^{\text {rd }} 1999$ case

292 were performed. The main aim of this study is to implement the diagnostic relations for $N_{0 x}$ 293 within a single-moment microphysics scheme and determine how well such a single-moment 294 scheme reproduces the results of double-moment scheme. Two baseline simulations are first 295 produced, using the original MY1, MY2 schemes, respectively. The results of the diagnostic $N_{0 x}$ 296 simulations are compared against these to gauge the impact and effectiveness of the diagnostic

297 relations. Another simulation was performed using the original MY1 scheme with $N_{0 r}$ lowered 298 from $8 \times 10^{6} \mathrm{~m}^{-4}$ to $4 \times 10^{5} \mathrm{~m}^{-4}$. Two further simulations were performed using the derived 299 diagnostic $N_{0 x}$ relations, one in which only the warm rain processes used the diagnostic relation, 300 and one in which the intercept parameters for both warm rain and ice processes, including 4 301 precipitating hydrometeors total, are diagnosed. Details of the simulations and the nomenclature 302 used can be found in Table 2.

303 Each simulation was performed using the same model (ARPS) as the 250-m reference 304 simulation that produced the synthetic dataset used for fitting the diagnostic relations. However, 305 rather than the complex full physics real-data setup of the reference simulation, the simulations 306 herein used the same single sounding and thermal bubble initialization procedure as in the 307 idealized experiments of Dawson et al. (2010), and were performed at the same horizontal 308 resolution of $500 \mathrm{~m}$. The use of this idealized model setup allows more control over the 309 experiments, and represents at least part of the natural variability among storms and their 
310 environment. It also facilitates direct comparison with the results of Dawson et al. (2010). The

311 simulations MY1_orig and MY2_orig are identical to MY1 and MY2 from Dawson et al. (2010)

312 and are repeated here mainly for convenience.

313 Fifty three vertical levels were used with vertical grid stretching employed, giving a

314 vertical grid spacing of $20 \mathrm{~m}$ at the surface that decreases to $800 \mathrm{~m}$ at the upper boundary, the

315 same as in the $250 \mathrm{~m}$ reference simulation. The fourth-order monotonic computational mixing

316 scheme of Xue (2000) was utilized with a coefficient of $0.0015 \mathrm{~s}^{-1}$. Each simulation used a

317 different microphysical scheme setup, although all of these were based on either the MY1 or

318 MY2 schemes (Milbrandt and Yau 2005b). The initial ellipsoidal thermal bubble used to trigger

319 the storm had a maximum potential temperature perturbation of $4 \mathrm{~K}$, horizontal radius of $10 \mathrm{~km}$

320 and vertical radius of $1.5 \mathrm{~km}$, and was centered $1.5 \mathrm{~km}$ above the surface, $35 \mathrm{~km}$ from the west

321 edge and $25 \mathrm{~km}$ from the south edge of the domain, which was of horizontal dimensions $128 \mathrm{~km}$

$322 \times 175 \mathrm{~km}$. The sounding used in the simulation was extracted from a 1-hour forecast of an earlier

$3233 \mathrm{~km}$ real-data simulation of this case, at a location upstream of the low-level inflow of the

324 storms. This was the same sounding used in Dawson et al. (2010), and full details of the original

325 real-data simulation can be found in Dawson et al. (2007).

326

$327 \quad$ 5. Results and discussion

328 a. Reflectivity structure

329 The MY1_orig simulation produced a storm that did not show realistic mature supercell

330 characteristics, as can be seen by the reflectivity structure (Fig. 5a). It must be noted that the

331 storm in MY1_orig was beginning to decay by one hour into the simulation, due to the strong

332 surging cold pool cutting off the updraft at the low levels in this simulation. The area of

333 maximum surface reflectivity, located around $60 \mathrm{~km}$ from the western and $80 \mathrm{~km}$ from the 
334 southern boundary of the domain, shows a maximum around $55 \mathrm{dBZ}$, although the lateral extent 335 of the forward flank reflectivity region is smaller than we would expect for an event of this type.

336 The forward flank reflectivity region is more realistically represented in MY2_orig (Fig.

337 5b) than it is in the single-moment simulation, although in MY2_orig the forward flank

338 reflectivity region is larger than expected. Morrison and Milbrandt (2011) found that the MY

339 schemes produce long and narrow forward flank regions. This does not affect the key point of

340 this paper since we are primarily interested in how well the results of the single-moment scheme

341 can match the double-moment, as a proof-of-concept. The relative improvement in the forward

342 flank reflectivity region in MY2_orig could be because the storm in MY1_orig decayed shortly

343 after the time examined here, while the storm in MY2_orig correctly sustained. However, there

344 are many processes that cannot be well represented within the single-moment scheme, such as

345 size sorting. In contrast, the double-moment scheme does parameterize size sorting, although

346 when the shape parameter $\alpha$ is set to 0 (as in MY2_orig), excessive size sorting tends to occur

347 (Milbrandt and Yau 2005a). The effect of this excessive size sorting can be noted in Fig. 5b, in

348 the sharp gradient at the leading edge of the forward flank reflectivity. Simulations of this case

349 performed using the triple-moment Milbrandt and Yau microphysics scheme produced a more

350 gradual and realistic reflectivity gradient in this region (see Fig. 3 in Dawson et al., 2010),

351 corresponding more closely to radar observations of this case (Dawson et al. 2010). $M Y 1 \_N O$, in which the rain intercept parameter value is reduced, is seen to produce a

353 more realistic storm structure than MY1_orig, particularly on the leading edge or forward flank

354 of the storm. The maximum reflectivity in this simulation is $61 \mathrm{dBZ}$, which is close to that of 355 MY2_orig, and significantly increased from that of MY1_orig. Since the only difference between 356 the two simulations is the reduction in the (fixed) value of $N_{0 r}$, this would seem to indicate that 
357 the default value of $8 \times 10^{6} \mathrm{~m}^{-4}$ for $N_{0 r}$ is too high for the type of severe convective case being

358 simulated here, it will clearly not be optimized as the default Marshall-Palmer relation was

359 derived for stratiform rain. For a given water content, increasing $N_{0 r}$ will decrease the median

360 volume diameter, resulting in decreased reflectivity values. As was shown by Snook and Xue

361 (2006), altering the intercept parameters for rain and hail PSDs can have a large impact on

362 tornadogenesis, so we expect that reducing $N_{0 r}$ will result in significant changes in several fields.

363 Despite the improved overall structure of the storm, the areal extent of the forward flank

364 reflectivity region in MY1_NO is still significantly smaller compared to that in MY2_orig. The

365 areal extent of reflectivity values greater than $30 \mathrm{dBZ}$ is $110 \mathrm{~km}^{2}$ in MY1_orig, $1072 \mathrm{~km}^{2}$ in

366 MY2_orig and $180 \mathrm{~km}^{2}$ in MY1_NO. For a threshold value of $50 \mathrm{dBZ}$, the corresponding areas

367 covered are $10 \mathrm{~km}^{2}, 52 \mathrm{~km}^{2}$ and $43 \mathrm{~km}^{2}$ respectively, illustrating the large forward flank region 368 in MY2_orig.

369 The reflectivity structure produced by diag_rain is broadly similar to that of MY1_NO, 370 although the lateral extent of the storm is slightly increased. The maximum reflectivity is similar

371 to MY1_N0 and MY2_orig. The forward flank region is better represented in diag_rain than in

372 the fixed- $N_{0 r}$ experiments, with the strength of the east-west reflectivity gradient in the forward

373 flank region being decreased in diag_rain (the reflectivity decreases to zero more gradually from

374 west to east), which corresponds more closely to base reflectivity observations from KTLX $\left(0.5^{\circ}\right.$

375 tilt, not shown). The area with reflectivity greater than $30 \mathrm{dBZ}$ is $215 \mathrm{~km}^{2}$ and that with greater 376 than $50 \mathrm{dBZ}$ is $54 \mathrm{~km}^{2}$.

377 While diagnosing the intercept parameter of the rain PSD produces improvement over the 378 original fixed- $N_{0 r}$ single-moment simulation, the improvement is mostly limited to the lowest 379 levels, since the same ice phase processes are used in diag_rain as MY1_orig, and little 
improvement is observed above the freezing level. At the surface, improvements in diag_rain in

381 the forward flank region are still relatively small; it is hypothesized that this is because much of

382 the liquid water in this region originates from melting and fallout from the anvil region, which is

383 not well simulated by the fixed- $N_{0}$ experiments.

384 To investigate possible further improvements to the solution in the forward flank region,

385 the diagnostic relations for the intercept parameters of snow, hail and graupel are implemented in 386 diag_all. Examining the reflectivity structure generated by diag_all, (Fig. 5e) it is clear that the 387 inclusion of diagnostic intercept parameters for graupel, snow and hail has a large effect on the 388 lateral extent of the storm and general storm structure. The overall reflectivity structure is seen to 389 resemble that of MY2_orig more closely than any other simulations. Particular improvement 390 (again, "improvement" is defined relative to the MY2_orig simulation) is noticed in the forward 391 flank region of the storm, with that of diag_all larger in size than in the other single-moment 392 simulations. This increased areal extent in diag_all is mostly of reflectivity values below 30 $393 \mathrm{dBZ}$, as the area covered with reflectivity of $30 \mathrm{dBZ}$ is $205 \mathrm{~km}^{2}$, which is lower than the 394 corresponding area for diag_rain, although the area with reflectivity over $20 \mathrm{dBZ}$ is greater for 395 diag_all than diag_rain. This would suggest that by diagnosing the intercept parameters for the 396 frozen categories, we are able to more accurately represent the ice processes that contribute to 397 fall-out from the anvil. However, the maximum reflectivity seen in diag_all is reduced by around $39810 \mathrm{dBZ}$ from that of MY2_orig, to $43 \mathrm{dBZ}$, which is lower than we would expect for a storm of 399 this nature. The lower reflectivity in diag_all than diag_rain is a consequence of a significant 400 decrease in rain water mixing ratio seen in this simulation (Fig. 6). The maximum rain water 401 mixing ratio at the surface in diag_all is $0.5 \mathrm{~g} \mathrm{~kg}^{-1}$, over four times less than the maximum of 2.2 $402 \mathrm{~g} \mathrm{~kg}^{-1}$ in diag_rain. The horizontal-plane-maximum rain water mixing ratio in diag_all is less 
403 than that in single-moment simulations at the $2 \mathrm{~km}$ height (Fig. 6) and it continues to decrease

404 toward the surface. The cold pool in diag_all is much weaker than the other single-moment 405 simulations (Fig. 8), resulting in more evaporation and decreased liquid rain water content, 406 directly impacting the reflectivity.

Although it is expected that the greatest improvement will be seen at levels below the 408 melting layer, the reflectivity structure is also examined at $5.5 \mathrm{~km}$ height. MY1_NO and 409 diag_rain show little improvement over MY1_orig (Figs. 7a, 7c, 7d), which is expected as only 410 the rain PSD is altered in these simulations. As at the surface, the forward flank reflectivity 411 region is larger in extent in MY2_orig than the single-moment simulations (Fig. 7b), although the

412 inclusion of the diagnostic relations for the frozen hydrometeors in diag_all (Fig. 7e) shows an 413 increase in the areal extent of this region. We note here that the reflectivity calculation in each 414 case is consistent with the DSD models used in each simulation.

415

b. Cold pool structure

417 The cold pool is discussed in terms of the equivalent potential temperature perturbation $418\left(\theta_{e}^{\prime}\right)$ fields at the surface, as in Dawson et al (2010), since the $\theta_{e}^{\prime}$ field also takes into account 419 moisture effects. Here, $\theta_{e}$ is calculated according to Bolton (1980). According to Dawson et al. 420 (2010), James and Markowski (2010) and McCaul and Cohen (2002), since $\theta_{e}$ is a conserved 421 variable even in the presence of moist processes, $\theta_{e}$ can be used as an estimation for the source 422 region of the air in the cold pool; below the level of minimum $\theta_{e}$, lower values of $\theta_{e}$ indicate a 423 higher source level of the surface air. Of course, the above statement assumes that $\theta_{e}$ is 424 conserved in the downdraft, which is not strictly true. If turbulent mixing with the environment 425 occurs, or any process that causes a departure from pseudoadiabatic descent (such as the melting 426 of frozen hydrometeors) then $\theta_{e}$ will not be exactly conserved. 
The cold pool produced in MY1_orig is seen to be very strong (Fig.8a). In fact, it is the

428 strength of the cold pool which cuts off the updraft after one hour and causes the simulated storm

429 to decay. This process is believed to be responsible for the mis-allignment of the low-level gust

430 frontal forcing and the mid-level mesocyclone that causes the failure in tornadogenesis in Snook

431 and Xue (2008). MY1_orig also produces a strong cold pool in the forward flank region of the

432 storm, which was not observationally verified for this case. Mobile mesonet observations from

433 May $3^{\text {rd }}$ indicate that the cold pools in the forward flank region of the storm for this event were

434 small and weak, with maximum temperature deficits of no more than 2-3 K (Markowski 2002).

435 The maximum temperature deficit in MY1_orig is close to $8 \mathrm{~K}$ (not shown). The areal extent of

436 the cold pool is examined through two metrics, the areas within which the $\theta_{e}$ deficit is greater

437 than $5 \mathrm{~K}$ and $10 \mathrm{~K}$. For MY1_orig, the areas are $680.5 \mathrm{~km}^{2}$ and $451 \mathrm{~km}^{2}$ for $\theta_{e}$ deficit exceeding

$4385 \mathrm{~K}$ and $10 \mathrm{~K}$, respectively.

439 The cold pool in MY2_orig is very weak in comparison, with a maximum temperature

440 deficit of $0.7 \mathrm{~K}$ (not shown), which is weaker than the cold pool observed by the mobile mesonet

441 (Markowski 2002). The cold pool in the $250 \mathrm{~m}$ reference simulation is stronger than that seen in

442 MY2_orig, and corresponds more closely to mobile mesonet observed temperature perturbations

443 (Dawson 2009) which suggests that MY2_orig simulation at 3600s is producing a storm that is

444 low-precipitation (LP) in character, as storm A was during its developing stage. The reduced

445 strength of the cold pool in the forward flank region in MY2_orig as compared to MY1_orig also

446 corresponds more closely to the mobile-mesonet-observed weak cold pool in this region

447 (Markowski 2002). The maximum $\theta_{e}$ deficit is reduced to $18 \mathrm{~K}$ for MY2_orig from $30 \mathrm{~K}$ for

448 MY1_orig, and the areas of $5 \mathrm{~K}$ and $10 \mathrm{~K} \theta_{e}$ deficits decrease to $105 \mathrm{~km}^{2}$ and $32 \mathrm{~km}^{2}$

449 respectively. 
The cold pool produced by $M Y 1_{-} N O$ is weaker than that of the original single-moment

451 scheme, with a maximum temperature deficit of $4 \mathrm{~K}$, a $5 \mathrm{~K} \theta_{e}$ deficit covering $365 \mathrm{~km}^{2}$ and a 10

$452 \mathrm{~K}$ deficit covering $201 \mathrm{~km}^{2}$. Snook and Xue (2008) found that simulations performed using

453 reduced values for $N_{0 r}$ and $N_{0 h}$ tend to produce a relatively weak cold pool when compared to

454 simulations performed using increased intercept parameter values. They concluded that this is

455 due to distributions that favor fewer large drops (as characterized by a reduced intercept

456 parameter) possessing a reduced total hydrometeor surface area when compared to the same

457 mass of water distributed as a large number of smaller drops. This reduced surface area limits the

458 potential for evaporative cooling, which is one of the most important mechanisms for cold pool

459 formation. Ice processes also play an important role in cold pool formation, and this is discussed

460 next.

The cold pool structure of diag_rain is intermediate between $M Y 1 \_$orig and MY1_NO in

462 terms of both maximum strength and areal coverage. The cold pool produced by diag_rain is

463 larger than that produced by $M Y 1_{-} N O$ (Figs. 8c, 8d). It seems that diagnosing $N_{0 r}$ does not

464 improve the simulation in terms of the cold pool structure and intensity as much as simply

465 reducing $N_{0 r}$ by a factor of 20 ; diagnostic treatment of the frozen hydrometeors may still be

466 needed for more realistic simulation of the cold pool. While the cold pool in MY1_NO is weaker,

467 we know the fixed $N_{0 r}$ value throughout the domain is not physically realistic.

The cold pool produced by diag_all that does include diagnostic treatment of ice PSDs is

469 much weaker than the cold pool witnessed in any of the previous single-moment simulations.

470 The maximum temperature deficit is $1.3 \mathrm{~K}$ (not shown), which is close to the maximum

471 temperature deficit of $0.7 \mathrm{~K}$ in MY2_orig, and is closer to the observed cold pool intensity

472 (Markowski 2002). The single-moment microphysics schemes, at least with their default 
473 intercept parameter values, tend to produce unrealistically strong cold pools. This is partly due to

474 the default values not necessarily being suitable for strong convective simulations. The

475 diagnostic approach shows promise in producing more realistic cold pools without excessive

476 intercept parameter tuning. The $\theta_{e}{ }^{\prime}$ field (Fig. 8e) for diag_all also shows a similar cold pool

477 structure to that of MY2 orig, with the maximum $\theta_{e}$ deficit of $-18.9 \mathrm{~K}$ (Fig. 8e) matching closely

478 that of $-18 \mathrm{~K}$ produced by MY2 orig and the areal extent of the $10 \mathrm{~K} \theta_{e}$ deficit at $47 \mathrm{~km}^{2}$ close to

479 that of MY2_orig at $32 \mathrm{~km}^{2}$. Although reducing the strength of the cold pool may not be

480 desirable in all cases, the goal of this study is to recreate the key features of the double-moment

481 scheme, which in this case presented with a cold pool of significantly reduced strength from the

482 single-moment simulation.

483

484 c. Second moment of the distribution

The striking differences in storm structure and cold pool between MY1_orig and MY1_NO

486 exemplify the large impact that PSD parameters can have upon the simulation results. Altering $487 N_{0 x}$ affects the simulation both directly through the impact on $N_{t x}$, and also indirectly through 488 feedback from processes such as evaporative effects. The second moment $\left(M_{2}\right)$ of the distribution 489 is closely related to the surface area of the hydrometeors, and as such it is the most important 490 moment for the evaporation rate. $M_{2}$ can be calculated using Eq. 3 and can be used to gain 491 insight on the evaporation rate.

492 For each simulation, the average second moment was calculated for two thresholds; the 493 average over all non-zero $M_{2}$ values in the simulation and the average over all points with 494 reflectivity greater than $30 \mathrm{dBZ}$. The second threshold was used as both MY2_orig and diag_all 495 have large regions of low reflectivity in the forward flank region, which will bias the average $M_{2}$ 
496 value. Across all non-zero valued points, the average value of $M_{2}$ for $M Y 1$ orig is $103.4 \mathrm{~mm}^{2} \mathrm{~m}^{-}$ $497{ }^{3}$, for MY1_NO is $68.9 \mathrm{~mm}^{2} \mathrm{~m}^{-3}$, and for MY2_orig is $25.7 \mathrm{~mm}^{2} \mathrm{~m}^{-3}$. The corresponding values for 498 diag_rain and diag_all are 1.61 and $0.95 \mathrm{~mm}^{2} \mathrm{~m}^{-3}$, respectively. Clearly the large average $M_{2}$ in 499 MY1_orig indicates a high evaporation rate, inducing the very strong cold pool in that 500 simulation. Fig. 6 showed that MY1_NO and diag_rain had very similar horizontal-plane501 maximum mixing ratio profiles, so the difference in average $M_{2}$ can be explained by 502 consideration of the diagnostic relation for rain. The power in the relation is 0.566 , so for $W$ of $5030.041 \mathrm{~g} \mathrm{~m}^{-3}$ or below, a diagnosed $N_{0}$ would be decreased in diag_rain as compared to MY1_NO, 504 and $M_{2}$ is proportional to $N_{0}$. We expect less difference between the average $M_{2}$ values when 505 only higher mixing ratio values are considered. The reflectivity threshold is used as a proxy for 506 this. For areas over $30 \mathrm{dBZ}$, the average $M_{2}$ value for $M Y 1$ orig is $629.3 \mathrm{~mm}^{2} \mathrm{~m}^{-3}$, for MY2_orig 507 is $38.8 \mathrm{~mm}^{2} \mathrm{~m}^{-3}$, and for $M Y 1 \_N O$ is $230.9 \mathrm{~mm}^{2} \mathrm{~m}^{-3}$. The average $M_{2}$ for $M Y 1 \_N O$ quadruples 508 when thresholded at $30 \mathrm{dBZ}$, but for diag_rain it increases almost tenfold from 1.61 to $15.1 \mathrm{~mm}^{2}$ $509 \mathrm{~m}^{-3}$. This is indicative of higher water content bringing the diagnosed $N_{0}$ closer in line with the 510 fixed value. Thresholding at $30 \mathrm{dBZ}$ increases the average $M_{2}$ of diag_all to $6.0 \mathrm{~mm}^{2} \mathrm{~m}^{-3}$, a far 511 lower increase than the fixed $N_{0}$ simulations, illustrating the reduced mixing ratio values in 512 diag_all against the other simulations (also see Fig. 6).

513 We note here that even though similar results, in terms of the cold pool strength and 514 precipitation structure, seem obtainable by choosing a smaller fixed value of the rain intercept 515 parameter, in practice, it is difficult to predetermine what value should be used and the constant 516 fixed values are not necessarily realistic. For this reason, we believe the diagnostic relations hold 517 more promise; to say the least they provide spatial variability to the PSD parameters that appear 518 to be more physical. 
In terms of each of the variables examined in this study, consistent improvements are

520 seen in diag_rain over MY1_orig. Further improvements in examined variables in diag_all,

521 except for the weak reflectivity core, bring the results of that simulation further in line with

522 results produced by the double-moment simulation, consistent with the goal of this study. This is

523 encouraging, and it is suggested that the method of diagnosing the intercept parameters based on

524 independently predicted variables merits further investigation. We suggest that the diagnostic 525 relationships be derived for additional cases besides supercells to investigate the 526 representativeness of the relations derived in this study. An investigation into the dependence of

527 the diagnostic relations on variables other than water content, such as temperature and updraft 528 velocity, would also add value to this method. Although a diagnostic relation for $N_{0}$ brought the 529 simulation results closer to the double-moment results, we recognize that there is a limit to this 530 approach; there are intrinsic limits to the single-moment scheme. The diagnostic relation for $N_{0}$ 531 cannot fully represent all complex physical processes included in the double-moment scheme 532 such as dynamic size sorting.

\section{d. Evolution of surface RMS errors}

As the goal of this study was to recreate the key features of the double-moment

536 simulation through use of diagnostic relations for $N_{0 x}$ within the single-moment framework, the

537 evolution of RMS errors in the surface temperature and $\theta_{e}$ fields is examined. As we seek to 538 mimic the output of MY2_orig, RMS errors are calculated on the difference between the surface539 level temperature and $\theta_{e}$ fields of MY2_orig and the four single-moment simulations.

540 The RMS errors in the temperature and $\theta_{e}$ fields indicate that throughout the simulation 541 period, the cold pool in diag_all most closely matched that of MY2_orig (Fig. 9), while the cold 542 pool in MY1_NO resembled the double-moment simulation more closely than that of diag_rain. 
543 All of the simulations outperformed MY1_orig, with the RMS error in temperature of MY1_orig

544 consistently double that of $M Y 1_{-} N O$ and $40 \%$ higher than diag_rain (Fig. 9). These results lend

545 weight to the earlier assertion that diagnosing the intercept parameter for rain alone does not

546 offer enough improvement in the cold pool over selecting a fixed, reduced (but arbitrary and

547 perhaps tunable after the event) value for $N_{0 r}$, and the form of the frozen hydrometeor

548 distributions must also be considered in order to produce a more realistic cold pool intensity.

\section{Summary and conclusions}

The overall goal of this study was to establish and utilize a relationship between the PSD

552 parameters and the hydrometeor mass variables typically predicted in single-moment

553 microphysics schemes in the hope of producing results closer to those of double-moment

554 schemes. The PSD parameter chosen was the intercept parameter of the size distribution. It has

555 already been shown from disdrometer measurements that there is a measurable positive

556 correlation between the two variables (Zhang et al. 2008) and in this study we derived such

557 relationships based on the output of a realistic two-moment simulation. The original single-

558 moment Milbrandt and Yau microphysics scheme uses a fixed value for the intercept parameter

559 of the distribution of each hydrometeor species. Two control simulations were run using the

560 original single and double-moment microphysics schemes and these were used as the basis

561 against which all subsequent simulations in this study are compared.

562 Simply reducing the fixed value of $N_{0 r}$ by a factor of 20 showed improvements over

563 MY1_orig in terms of producing results more closely aligned with those of the double-moment

564 simulation (more realistic reflectivity structure, reduced cold pool strength, reduced number 565 concentration.) 
Diagnosing the intercept parameter of the rain PSD produced improvements upon the

567 original fixed- $N_{0 r}$ single-moment simulation, however, these are limited to the lowest levels. The

568 addition of a diagnostic relation for $N_{0 x}$ for the frozen hydrometeor categories is seen to have a

569 greater impact on the simulation results than diagnosing $N_{0 r}$ only. Improvements are seen at low

570 levels as well as above the melting layer, due to improvements in the structure of the frozen

571 categories bringing improvements in the rain category through fallout and melting.

572 The use of diagnostic relations for several frozen species was seen to significantly

573 increase the lateral extent of the storm in diag_all over the other single-moment simulations.

574 Extending the diagnostic intercept parameter relation to the frozen hydrometeors also has a large

575 positive impact on the cold pool structure. It is known that altering the intercept parameter of any

576 of the hydrometeor distributions can have a large effect on the cold pool, as altering the shape of

577 the distribution directly affects the rate of evaporative cooling (Snook and Xue, 2008, 2006;

578 Gilmore et al., 2004).

579 While diag_rain produced a cold pool smaller in size and strength than that of MY1_orig,

580 diagnosing the frozen category intercept parameters further reduced both the intensity and size of

581 the cold pool, bringing the temperature deficit in line with that of MY2_orig. The cold pool in

582 MY2_orig was seen to be very weak in the forward flank region, which agrees with surface

583 mesonet observations from the event (Markowski 2002), hence improvements in the

584 representation of the forward flank region through diagnosing the intercept parameters of the

585 frozen species is encouraging.

586 While improvements are seen for the use of the diagnostic relations within these simulations,

587 questions still exist about the representativeness of the derived $N_{0 x}-W_{x}$ relations, especially in

588 light of the significantly decreased reflectivity core in diag_all. This could be investigated 
through the performance of simulations for a number of other cases. If the relations derived here

590 are too case-specific, the inclusion of other cases into the study would allow us to derive a more

591 general relation for each species. If relations are derived that diagnose $N_{0 x}$ for each of the

592 precipitating hydrometeor species and are applicable to a range of different cases (for example

593 severe convective storms, squall line cases, stratiform precipitation and winter storms), then this

594 method shows considerable promise in improving the results of a six-prognostic-variable single-

595 moment microphysics scheme, with considerably less increase in computational

596 cost as compared to using a twelve-prognostic-variable double-moment scheme. It is hoped that

597 through further exploration of the parameter space a set of relations can be derived that will be

598 applicable to a range of situations. A further simulation was performed to investigate the

599 specificity of the derived relations. The same model setup was used, with $N_{0 x}$ for each species

600 diagnosed using the derived relations, but with the power in the diagnostic relations (see Table 1)

601 set to 1 for each species. Results (not shown) were very similar to that of diag_all, which

602 indicates that results seem to be not very sensitive to the exact value in the coefficient of the

603 power law but further investigation is needed to ascertain this.

606 Acknowledgement This study was primarily supported by NSF grants AGS-0608168, AGS-

6070802888 and AGS-1046171. The second author was also supported by NSF grants EEC608 0313747, OCI-0905040, AGS-0941491, AGS-0750790, and AGS-1046081. Computations were 609 carried out at the Oklahoma Supercomputing Center for Education and Research (OSCER), and 610 at the Texas Advanced Computing Center (TACC). The authors thank two anonymous reviewers 611 who contributed to the substantial improvement of the manuscript. 
614 Bolton, D., 1980: The computation of equivalent potential temperature. Mon. Wea. Rev., 108, 1046-1053.

616 Brewster, K., 1996: Application of a Bratseth analysis scheme including Doppler radar data. Preprints, 15th Conf. Wea. Anal. Forecasting, Norfolk, VA, Amer. Meteor. Soc., 92-95.

618 Brock, F. V., K. C. Crawford, R. L. Elliott, G. W. Cuperus, S. J. Stadler, H. L. Johnson, and M.D. Eilts, 1995: The Oklahoma Mesonet: A technical overview. J. Atmos. Oceanic Technol., 12, 5-19.

Brooks, H. E. and C. A. Doswell, 2002: Deaths in the 3 May 1999 Oklahoma City tornado from

Cao, Q., G. Zhang, E. Brandes, T. Schuur, A. Ryzhkov, and K. Ikeda, 2008: Analysis of Video a historical perspective. Wea. Forecasting, 17, 354-361.

Cao, Q. and G. Zhang, 2009: Errors in Estimating Raindrop Size Distribution Parameters Employing Disdrometer and Simulated Raindrop Spectra. J. Appl. Meteor. Climatol., 48, 406-425. Oklahoma. J. Appl. Meteor. Climatol., 47, 2238-2255.

Cooper, W. A., Ice initiation in natural clouds. Precipitation Enhancement-A Scientific Challenge, Meteor. Monogr., No. 43, Amer. Meteor. Soc., 29-32.

Dawson, D., 2009: Impacts of Single- and Multi-moment Microphysics on Numerical 635 Simulations of Supercells and Tornadoes of the 3 May 1999 Oklahoma Tornado Outbreak, Ph.D. Dissertation, School of Meteorology, University of Oklahoma, 173 pp.

Dawson, D. T., M. Xue, J. A. Milbrandt, and M. K. Yau, 2010: Comparison of Evaporation and Cold Pool Development between SIngle-Moment and Multimoment Bulk Microphysics 
Schemes in Idealized Simulations of Tornadic Thunderstorms. Mon. Wea. Rev., 138, $1152-1171$.

638 Dawson, D. T., II, M. Xue, J. A. Milbrandt, M. K. Yau, and G. Zhang, 2007: Impact of multi-

Fujita, T. T., 1971: A proposed characterization of tornadoes and hurricanes by area and Meteor. Soc., CDROM 10B.2. moment microphysics and model resolution on predicted cold pool and reflectivity intensity and structures in the Oklahoma tornadic supercell storms of 3 May 1999. 22nd Conf. Wea. Anal. Forecasting/18th Conf. Num. Wea. Pred., Salt Lake City, Utah, Amer.

Fuite, T. T., 1971: A proposed characteization of tomadoes and huricanes by area and intensity. Dept. of Geophysical Sciences, University of Chicago SMRP Res. Paper 91, 42 pp.

Gilmore, M. S., J. M. Straka, and E. N. Rasmussen, 2004: Precipitation uncertainty due to variations in precipitation particle parameters within a simple microphysics scheme. Mon. Wea. Rev., 132, 2610-2627.

Hu, M., M. Xue, and K. Brewster, 2006: 3DVAR and cloud analysis with WSR-88D level-II data for the prediction of Fort Worth tornadic thunderstorms. Part I: Cloud analysis and its impact. Mon. Wea. Rev., 134, 675-698.

James, R. P. and P. M. Markowski, 2010: A Numerical Investigation of the Effects of Dry Air Aloft on Deep Convection. Mon. Wea. Rev., 138, 140-161.

Kumjian, M. R. and A. V. Ryzhkov, 2008: Polarimetric signatures in supercell thunderstorms. $J$. Appl. Meteor. Climatol., 47, 1940-1961.

Kumjian, M. R. and A. R. Ryzhkiv, 2009: Storm-relative helicity revelaed from polarimetric radar measurements. J. Atmos. Sci., 66, 667-685. 
658 Lazarus, S., C. M. Ciliberti, J. D. Horel, and K. Brewster, 2002: Near-real-time applications of a 659 mesoscale analysis system to complex terrain. Wea. Forecasting, 17, 971-1000.

660 Lemon, L. R. and C. A. Doswell, 1979: Severe thunderstorm evolution and mesocyclone 661 structure as related to tornadogenesis. Mon. Wea. Rev., 107, 1184-1197.

662 Lin, Y.-L., R. D. Farley, and H. D. Orville, 1983: Bulk parameterization of the snow field in a 663 cloud model. J. Climat. Appl. Meteor., 22, 1065-1092.

664 Mallet, C. and L. Barthes, 2009: Estimation of Gamma Raindrop Size Distribution Parameters: 665 Statistical Fluctuations and Estimation Errors. J. Atmos. Oceanic Technol., 26, 1572$666 \quad 1584$.

667 Markowski, P. M., 2002: Mobile mesonet observations on 3 May 1999. Wea. Forecasting, 17, $668 \quad 430-444$.

669 Marshall, J. S. and W. M. Palmer, 1948: The distribution of raindrops with size. J. Meteor., 5, $670 \quad 165-166$.

671 McCaul, E. W. and C. Cohen, 2002: The Impact on Simulated Storm Structure and Intensity of 672 Variations in the Mixed Layer and Moist Layer Depths. Mon. Wea. Rev., 130, 1722-1748.

673 Milbrandt, J. A. and M. K. Yau, 2005a: A multi-moment bulk microphysics parameterization. 674 Part I: Aanlysis of the role of the spectral shape parameter. J. Atmos. Sci., 62, 3051-3064.

675 Milbrandt, J. A. and M. K. Yau, 2005b: A multi-moment bulk microphysics parameterization. 676 Part II: A proposed three-moment closure and scheme description. J. Atmos. Sci., 62,

678 Morrison, H. and J. A. Milbrandt, 2011: Comparison of two-moment bulk microphysics schemes 679 in idealized supercell thunderstorm simulations. Mon. Wea. Rev., 139, 1103-1130. 
Morrison, H., J. A. Curry, and V. I. Khvorostyanov, 2005: A new double-moment microphysics parameterization for application in cloud and climate models. Part I: Description. $J$. Atmos. Sci., 62, 1665-1677.

Murphey, H. V., R. M. Wakimoto, C. Flamant, and D. E. Kingsmill, 2006: Dryline on 19 June 2002 during IHOP. Part I: Airborne Doppler and LEANDRE II analyses of the thin line structure and convection initiation. Mon. Wea. Rev., 134, 406-430.

Roebber, P. J., D. M. Schultz, and R. Romero, 2002: Synoptic Regulation of the 3 May 1999 Tornado Outbreak. Wea. Forecasting, 17, 399-429.

Snook, N. and M. Xue, 2006: Sensitivity of tornadogenesis in very-high-resolution numerical simulations to variations in model microphysical parameters. Extended Abstract, Conf. Severe Local Storms, Amer. Meteor. Soc., CDROM 16.4.

Snook, N. and M. Xue, 2008: Effects of microphysical drop size distribution on tornadogenesis in supercell thunderstorms. Geophy. Res. Letters, 35, L24803, doi:10.1029/2008GL035866.

Speheger, D. A., C. A. Doswell, and G. J. Stumpf, 2002: The Tornadoes of 3 May 1999: Event Verification in Central Oklahoma and Related Issues. Wea. Forecasting, 17, 362-381.

Straka, J. M. and E. R. Mansell, 2005: A bulk microphysics parameterization with multiple ice precipitation categories. J. Appl. Meteor., 44, 445-466.

Thompson, R. L. and R. Edwards, 2000: An Overview of Environmental Conditions and Forecast Implications of the 3 May 1999 Tornado Outbreak. Wea. Forecasting, 16, 682699. 
701 Thompson, G., R. M. Rasmussen, and K. Manning, 2004: Explicit forecasts of winter 702 precipitation using an improved bulk microphysics scheme. Part I: description and sensitivity analysis. Mon. Wea. Rev., 132, 519-542.

704 Tokay, A. and D. A. Short, 1996: Evidence from tropical raindrop spectra of the origin of rain 705 from stratiform versus convective clouds. J. Appl. Meteor., 35, 355-371.

Ulbrich, C. W., 1983: Natural variations in the analytical form of the raindrop size distributions. J. Appl. Meteor., 22, 1764-1775.

van den Heever, S. C. and W. R. Cotton, 2004: The impact of hail size on simulated supercell storms. J. Atmos. Sci., 61, 1596-1609.

Van Weverberg, K., N. P. M. van Lipzig, and L. Delobbe, 2010: The impact of size distribution assumptions in a bulk one-moment microphysics scheme on simulated surface precipitation and storm dynamics during a low-topped supercell case in Belgium. Monthly Weather Review, 139, 1131-1147.

714 Van Weverberg, K., N. P. M. Van Lipzig, and L. Delobbe, 2011a: Evaluation of moist processes during intense precipitation in km-scale NWP models using remote sensing and in-situ

717 Van Weverberg, K., A. M. Vogelmann, H. Morrison, and J. Milbrandt, 2011b: Sensitivity of 718 idealized squall line simulations to the level of complexity used in two-moment bulk microphysics schemes. Monthly Weather Review.

720 Weigel, A. P., M. A. Liniger, and C. Appenzeller, 2008: Seasonal ensemble forecasts: Are 721 recalibrated single models better than multi-models? Mon. Wea. Rev., preprint, 00007220000 
723 Xue, M., 2000: High-order monotonic numerical diffusion and smoothing. Mon. Wea. Rev., 128, $724 \quad 2853-2864$.

725 Xue, M., K. K. Droegemeier, and V. Wong, 2000: The Advanced Regional Prediction System 726 (ARPS) - A multiscale nonhydrostatic atmospheric simulation and prediction tool. Part I: 727 Model dynamics and verification. Meteor. Atmos. Physics, 75, 161-193.

728 Xue, M., K. K. Droegemeier, V. Wong, A. Shapiro, K. Brewster, F. Carr, D. Weber, Y. Liu, and 729 D.-H. Wang, 2001: The Advanced Regional Prediction System (ARPS) - A multiscale 730 731

732 Zhang, G., J. Vivekanandan, and E. Brandes, 2001: A method for estimating rain rate and drop 733

735 Zhang, G., M. Xue, Q. Cao, and D. Dawson, 2008: Diagnosing the intercept parameter for 736

738 Zhang, G., J. Vivekanandan, E. A. Brandes, R. Meneghini, and T. Kozu, 2003: The Shape-Slope 739 exponential raindrop size distribution based on video disdrometer observations. J. Appl. Meteor. Climatol., 47, 2983-2992.

741

742 


\section{List of figures}

744 Fig. 1. Dependence of rain intercept parameter $\left(N_{0 r}\right)$ on water content $(W)$. Points are directly

745 fitted using the zeroth and third moments of the exponential DSD to obtain the $N_{0 r}-W$

746 relation. The dashed line is the derived fitted relation (in linear space) and the bold line

747 shows the fixed value of $N_{0 r}$ used in the original Milbrandt and Yau single-moment scheme.

748 Fig. 2. As in Fig. 1, but for snow.

749 Fig. 3. As in Fig. 1, but for graupel.

750 Fig. 4. As in Fig. 1, but for hail.

751 Fig. 5. Reflectivity and horizontal wind vectors at the surface (plotted every $2.5 \mathrm{~km}$ ) at $3600 \mathrm{~s}$

752 into the five simulations: a) MY1_orig, b) MY2_orig, c) MY1_NO, d) diag_rain and e) 753 diag_all.

754 Fig. 6. Horizontal-plane-maximum rain mixing ratio profiles at five levels in the lowest $2 \mathrm{~km}$.

755 Fig. 7. Reflectivity and horizontal wind vectors at $5.5 \mathrm{~km}$ height (plotted every $2.5 \mathrm{~km}$ ) for the 756 five simulations as in Fig. 5.

757 Fig. 8. Surface equivalent potential temperature perturbation (shaded) and reflectivity (contours, $758 \quad 10 \mathrm{dBZ}$ increment) for the five simulations as in Fig. 5.

759 Fig. 9. Evolution of the RMS error in equivalent potential temperature for each of the four 760 single-moment simulations when compared to MY2_orig. 
762 Table 1. The fixed $N_{0 x}$ values used in the original Milbrandt and Yau single-moment 763 microphysics scheme, and the derived diagnostic relation for $N_{0 x}$ (based on $W_{x}$ ) for rain, snow, 764 graupel and hail.

765

766

767

768

769

770

771

\begin{tabular}{|c|c|c|}
\hline Species & Default fixed $N_{0 x}$ values & $\begin{array}{c}\text { Diagnostic relation derived from } \\
\text { real data simulation }\end{array}$ \\
\hline Rain & $N_{0 r}=8 \times 10^{6} \mathrm{~m}^{-4}$ & $N_{0 r}=2.45 \times 10^{6} W_{r}{ }^{0.566} \mathrm{~m}^{-4}$ \\
\hline Snow & $N_{0 s}=3 \times 10^{6} \mathrm{~m}^{-4}$ & $N_{0 s}=3.19 \times 10^{9} W_{s}{ }^{0.755} \mathrm{~m}^{-4}$ \\
\hline Graupel & $N_{0 g}=4 \times 10^{5} \mathrm{~m}^{-4}$ & $N_{0 g}=6.13 \times 10^{8} W_{g}{ }^{0.523} \mathrm{~m}^{-4}$ \\
\hline Hail & $N_{0 h}=4 \times 10^{4} \mathrm{~m}^{-4}$ & $N_{0 h}=5.13 \times 10^{6} W_{h}{ }^{0.467} \mathrm{~m}^{-4}$ \\
\hline
\end{tabular}

Table 2. Description of the microphysical setup used in the five simulations that were performed at $500 \mathrm{~m}$ horizontal resolution.

\begin{tabular}{|c|l|}
\hline Experiment Name & \multicolumn{1}{|c|}{ Details of microphysics scheme } \\
\hline MY1_orig & Original single-moment Milbrandt and Yau scheme. \\
\hline MY2_orig & Original double-moment Milbrandt and Yau scheme. \\
\hline MY1_NO & Single-moment with reduced fixed value of $N_{0 r}=4 \times 10^{5} \mathrm{~m}^{-4}$. \\
\hline diag_rain & Single-moment with intercept parameter diagnosed for rain only. \\
\hline diag_all & $\begin{array}{l}\text { Single-moment with intercept parameter diagnosed for all } \\
\text { precipitating hydrometeor categories. }\end{array}$ \\
\hline
\end{tabular}




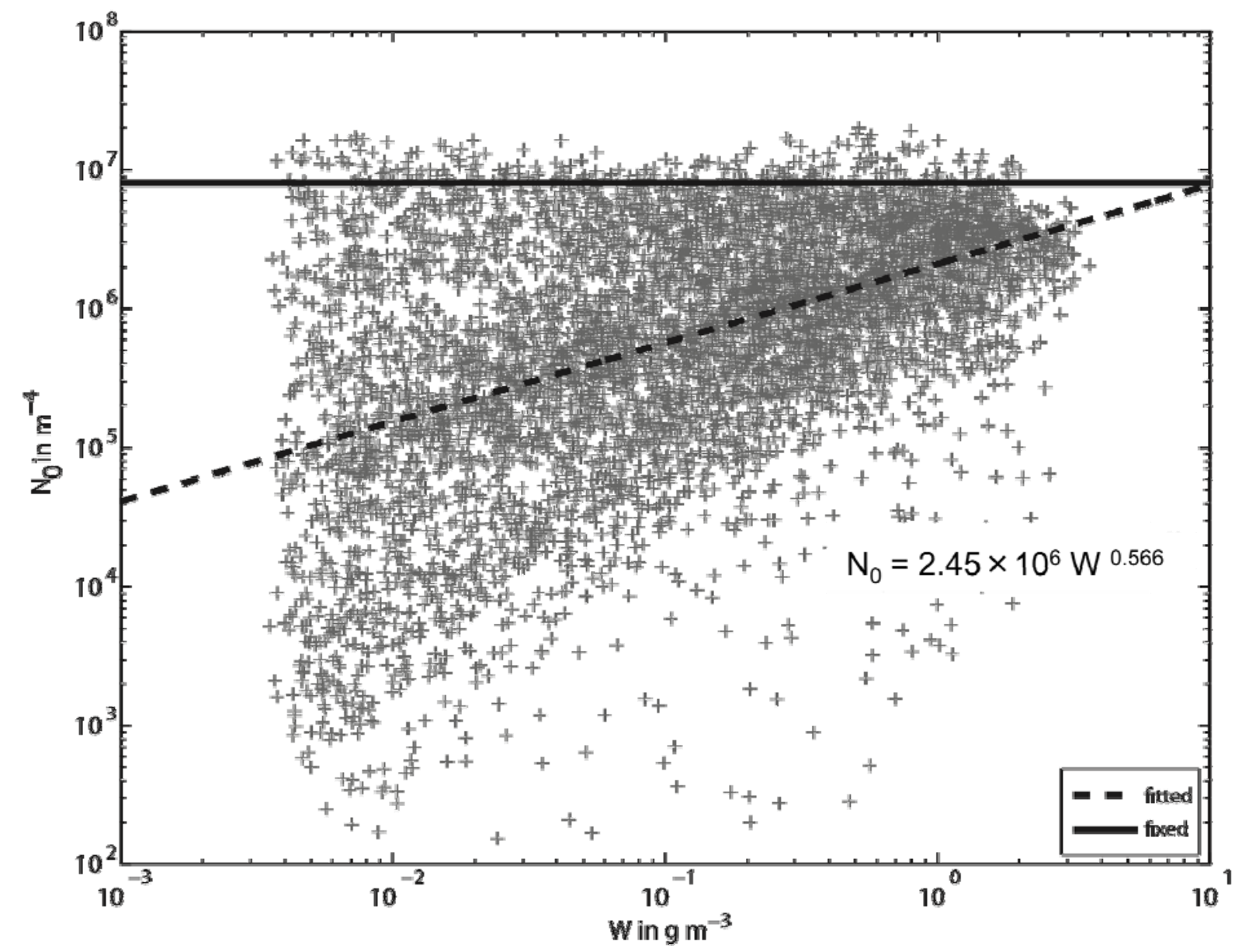

773 Fig. 1. Dependence of rain intercept parameter $\left(N_{0 r}\right)$ on water content $(W)$. Points are directly 774 fitted using the zeroth and third moments of the exponential DSD to obtain the $N_{0 r}-W$ relation. 775 The dashed line is the derived fitted relation (in linear space) and the bold line shows the fixed 776 value of $N_{0 r}$ used in the original Milbrandt and Yau single-moment scheme. 


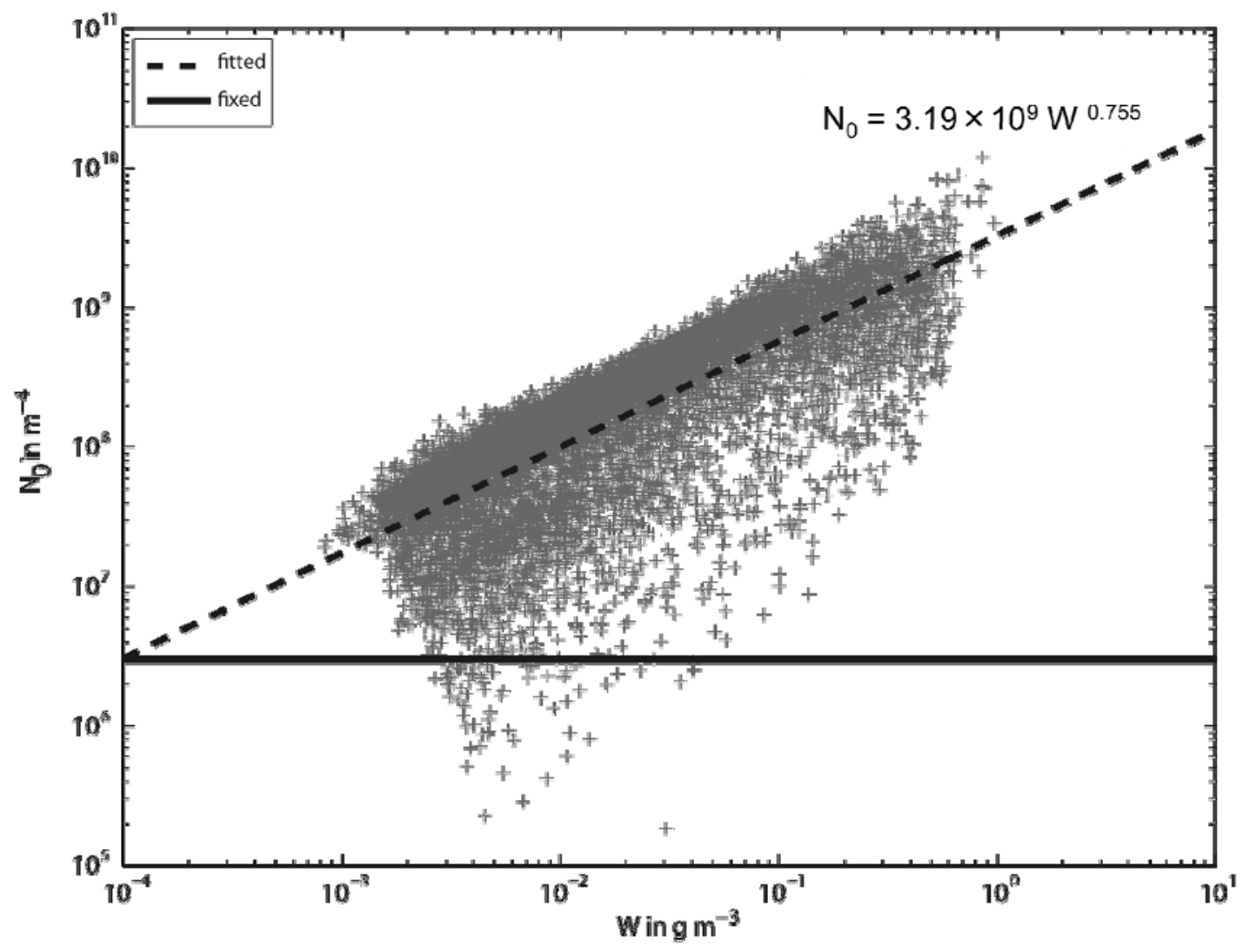

778

779

780

Fig. 2. As in Fig. 1, but for snow. 


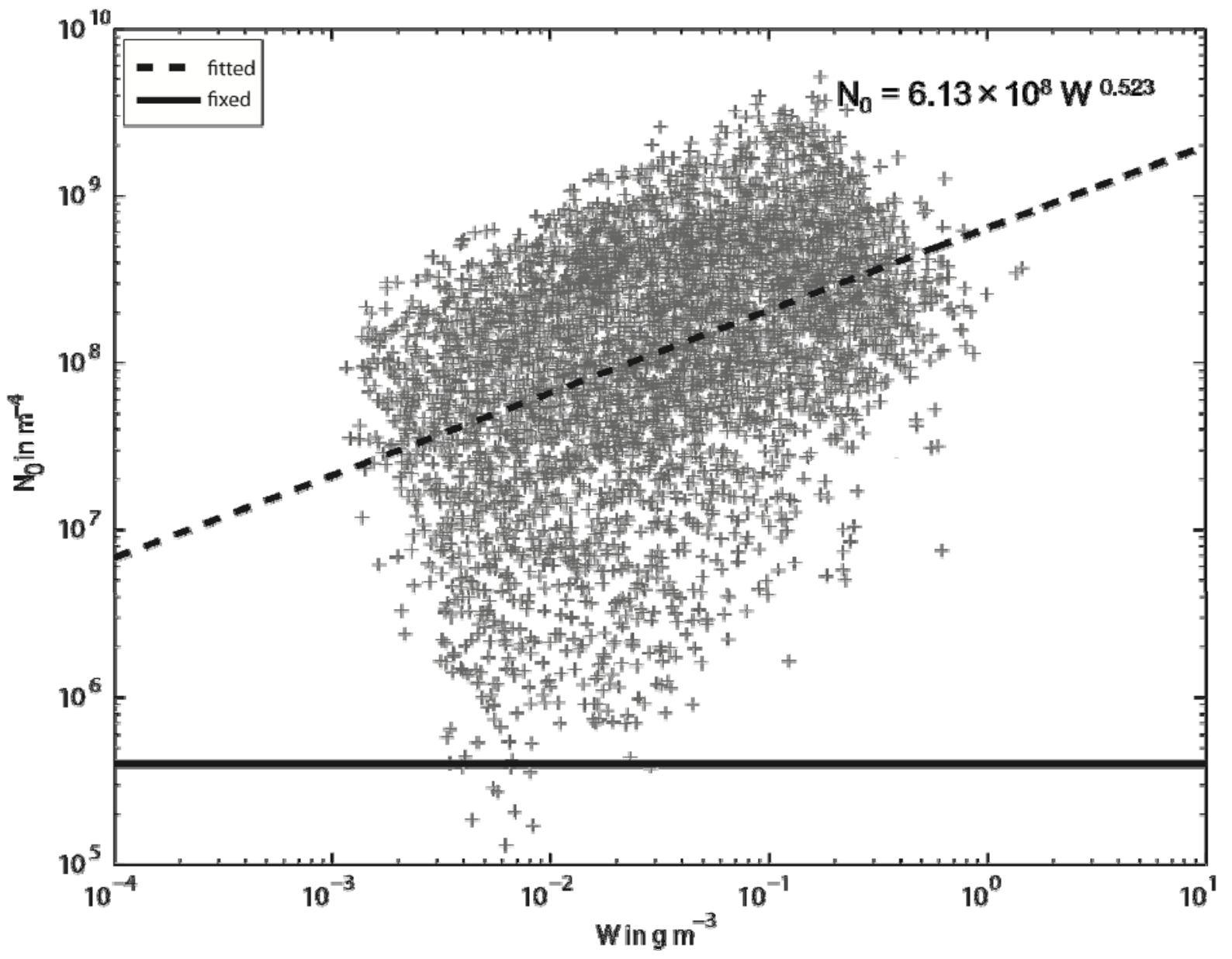

782

783

784

Fig. 3. As in Fig. 1, but for graupel. 


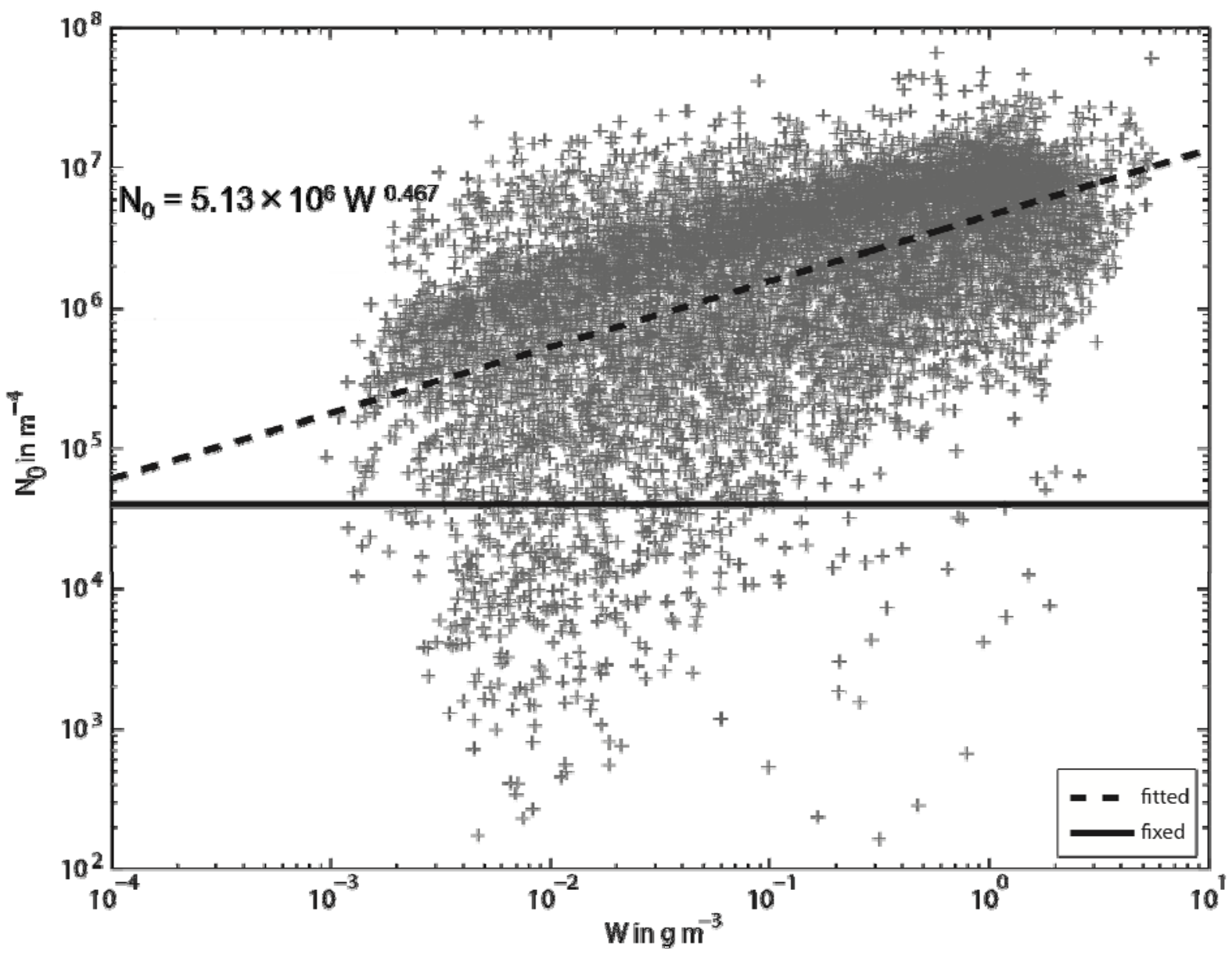

786

Fig. 4. As in Fig. 1, but for hail.

787 

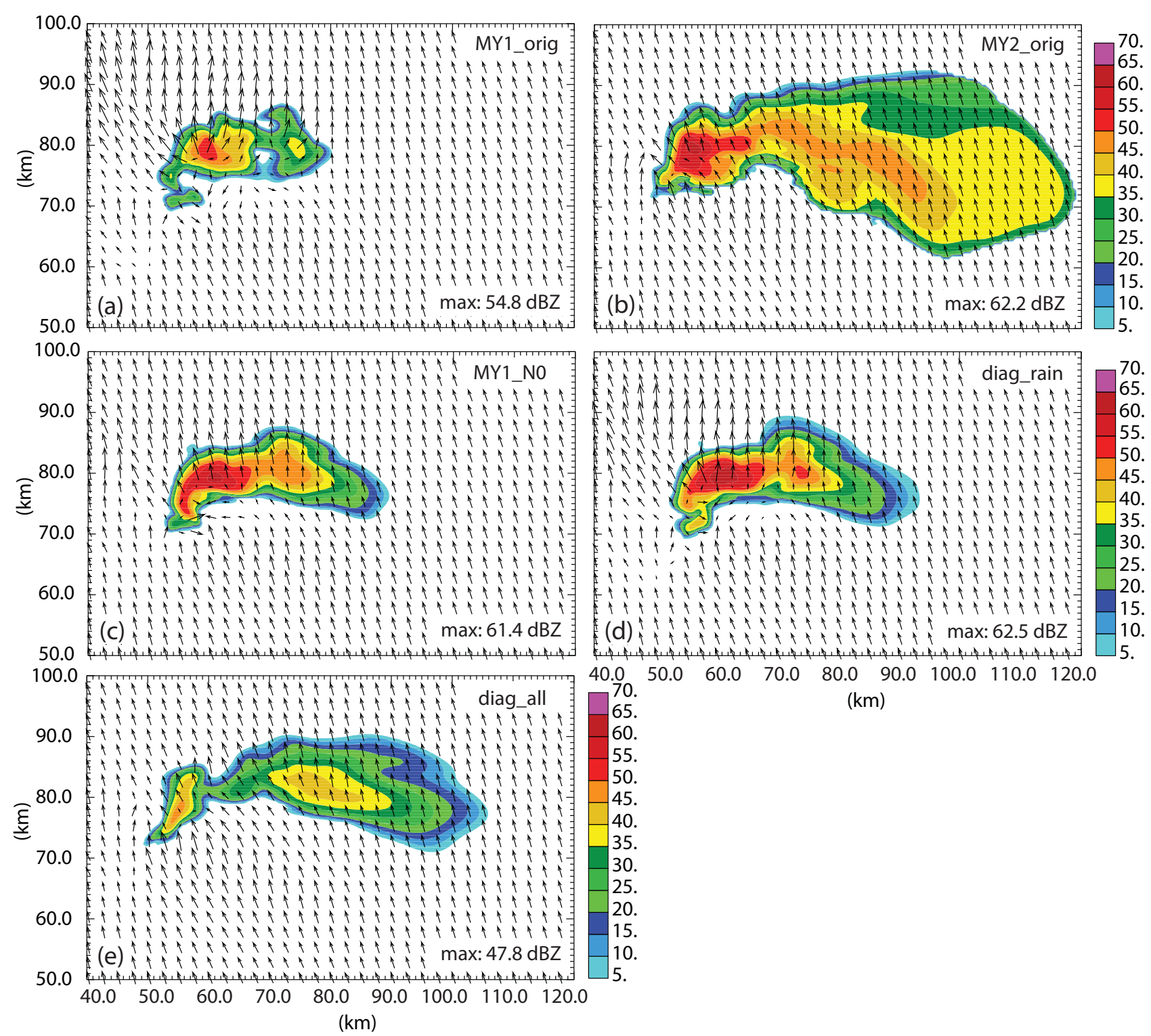

Fig. 5. Reflectivity and horizontal wind vectors at the surface (plotted every $2.5 \mathrm{~km}$ ) at $3600 \mathrm{~s}$ 790 into the five simulations: a) MY1_orig, b) MY2_orig, c) MY1_NO, d) diag_rain and e) diag_all. 


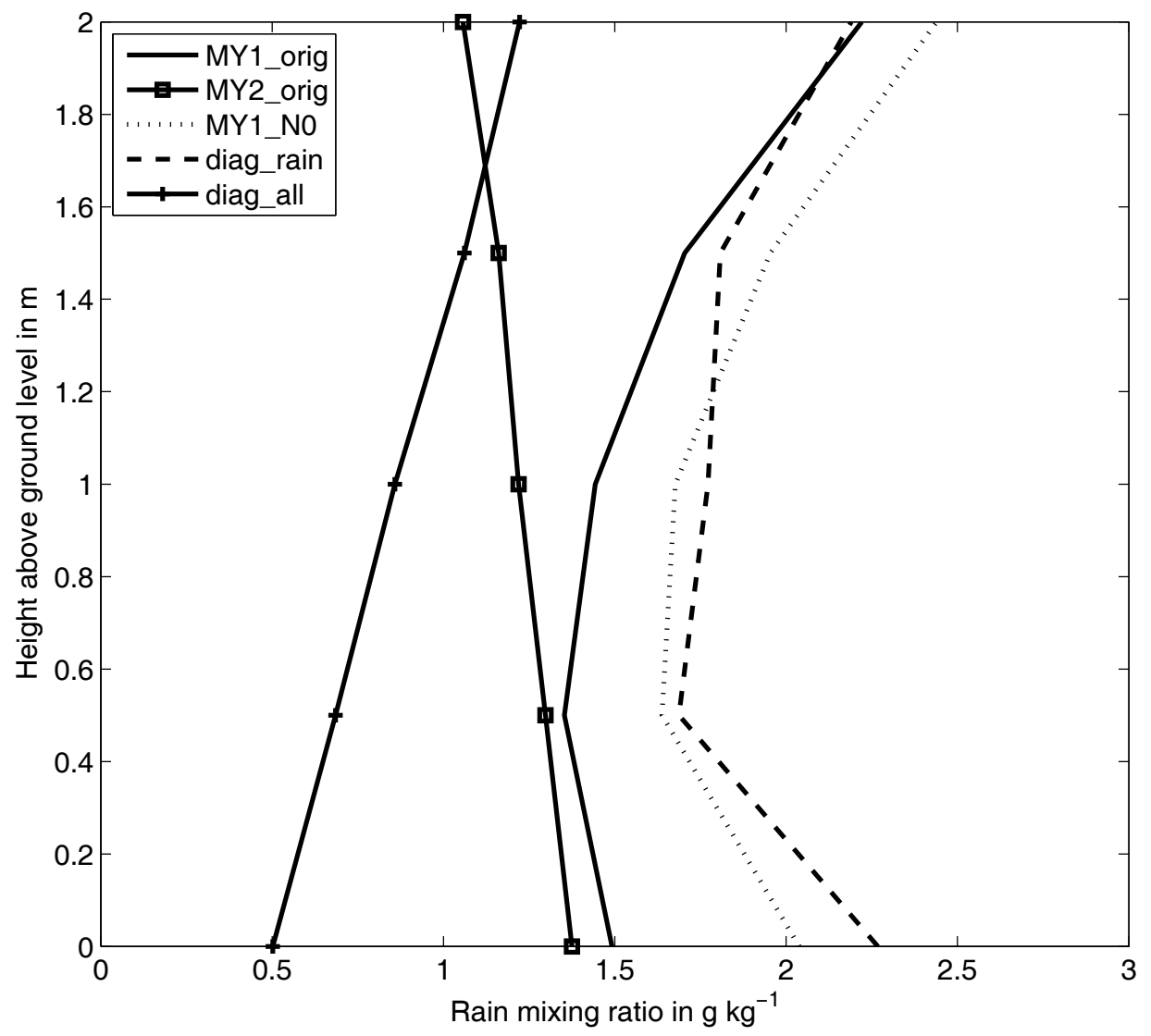

796

797 Fig. 6. Horizontal-plane-maximum rain mixing ratio profiles at five levels in the lowest $2 \mathrm{~km}$. 

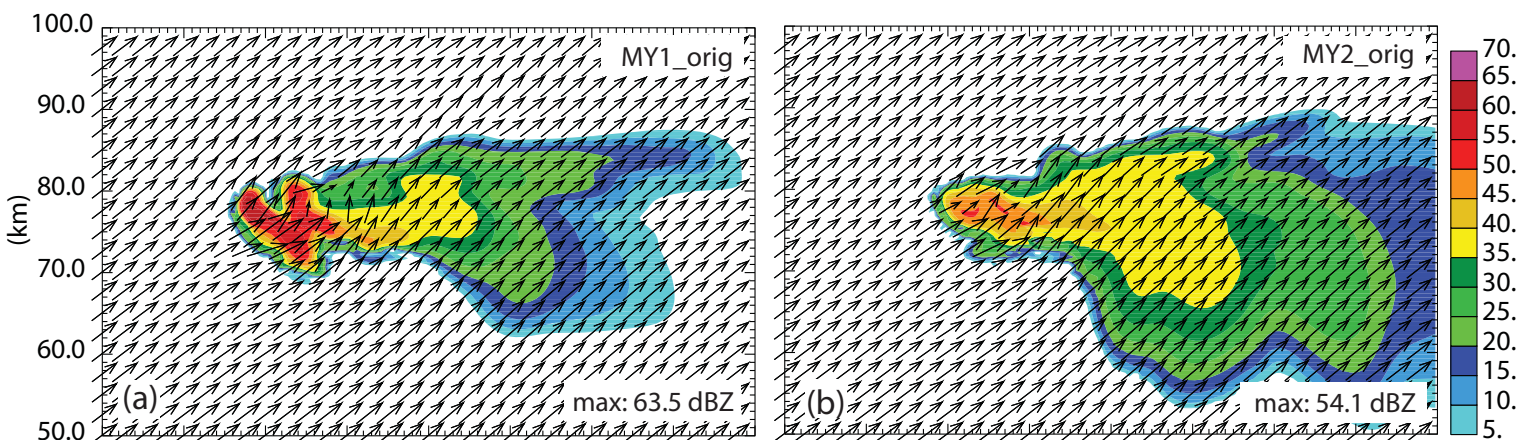

$$
100.0
$$
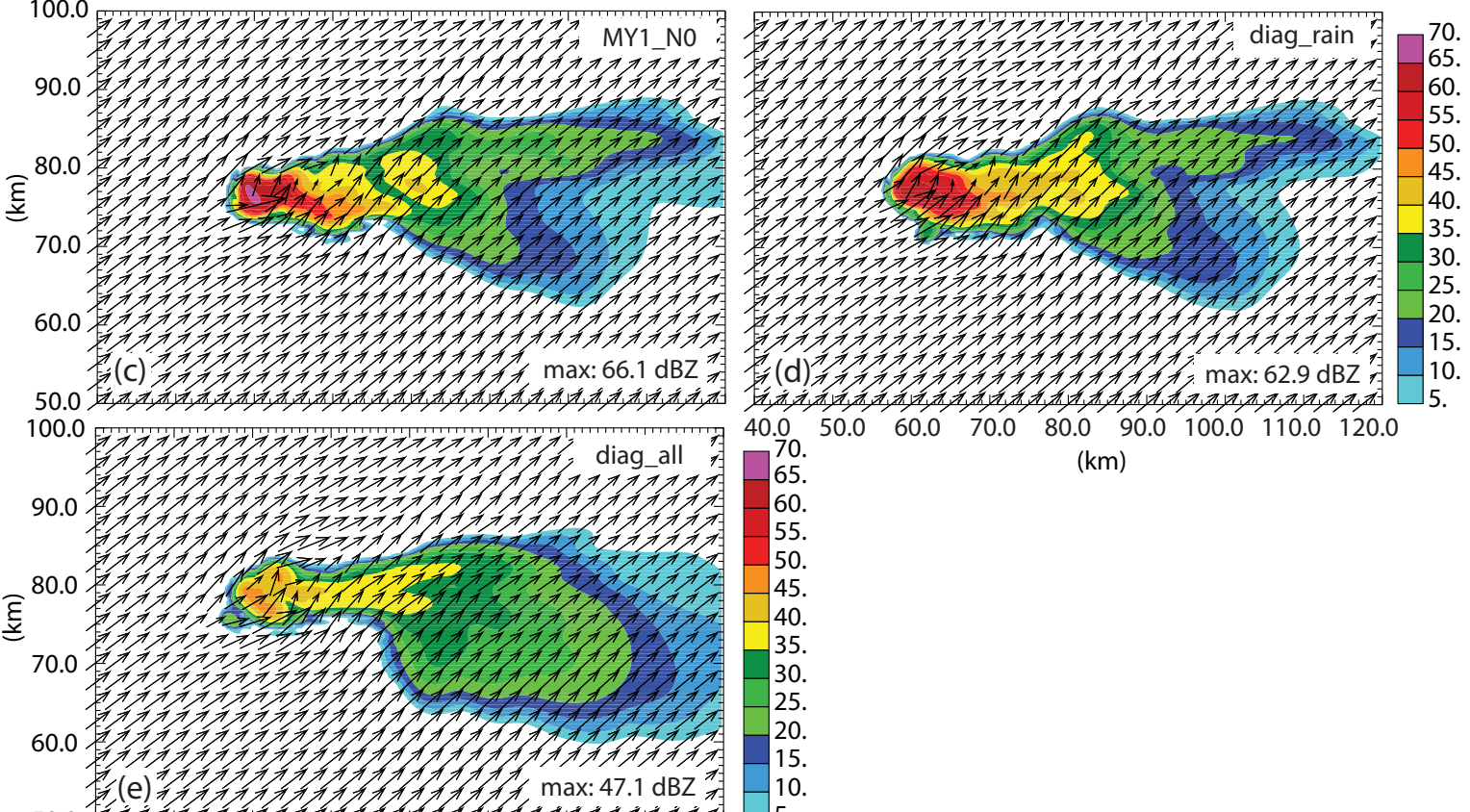

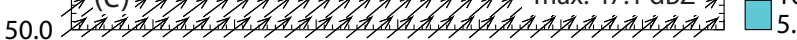

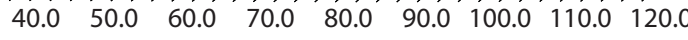

798

(km)

799 Fig. 7. Reflectivity and horizontal wind vectors at $5.5 \mathrm{~km}$ height (plotted every $2.5 \mathrm{~km}$ ) for the

800 five simulations as in Fig. 5.

801

802

803

804 


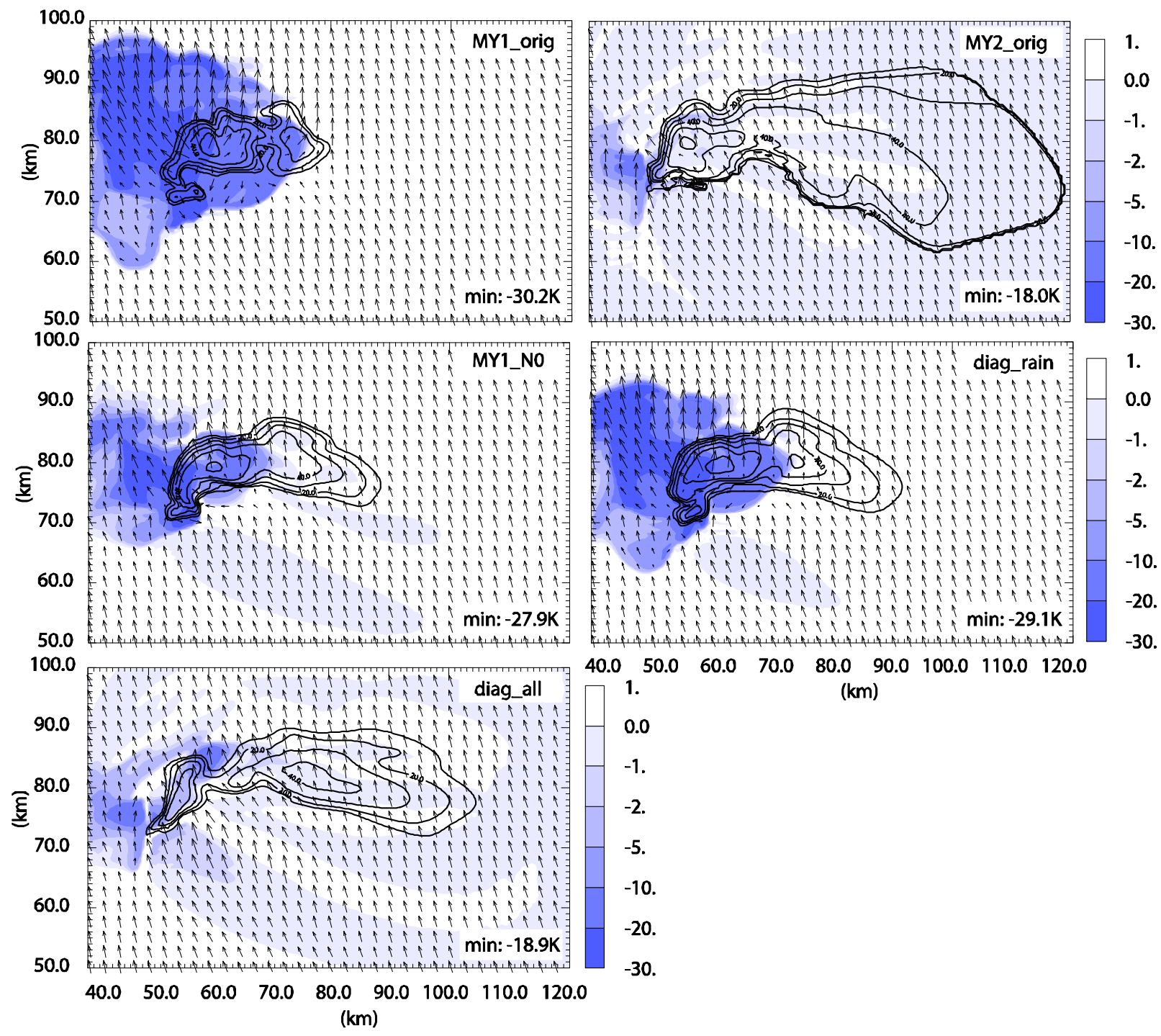
(km)

Fig. 8. Surface equivalent potential temperature perturbation (shaded) and reflectivity (contours, $10 \mathrm{dBZ}$ increment) for the five simulations as in Fig. 5.

808

809 


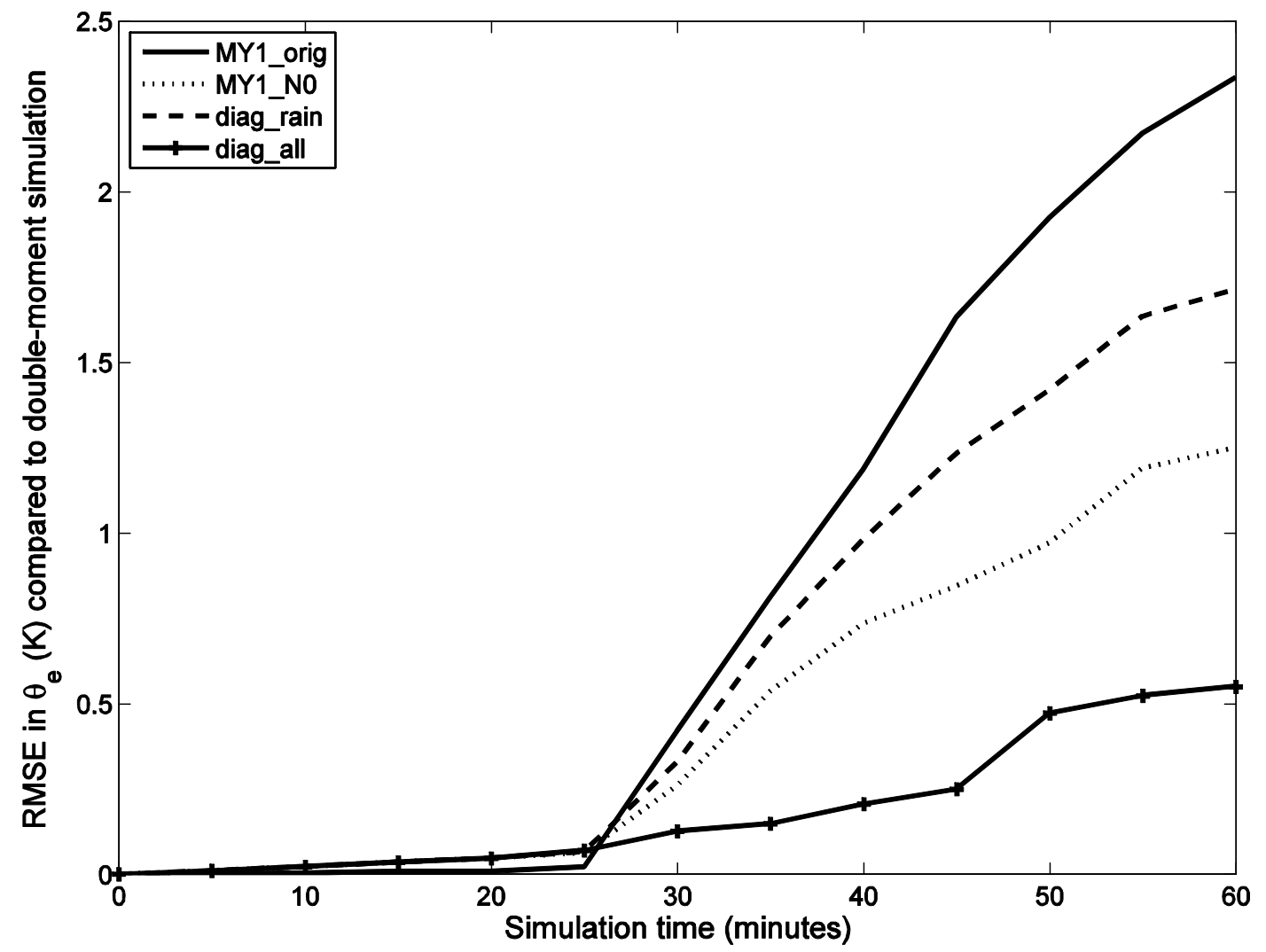

810

811 Fig. 9. Evolution of the RMS error in equivalent potential temperature for each of the four 812 single-moment simulations when compared to MY2_orig.

813 